\title{
Prior Bordetella pertussis infection modulates allergen priming and the severity of airway pathology in a murine model of allergic asthma
}

\author{
D. P. Ennis*, J. P. Cassidy† and B. P. Mahon* \\ *Mucosal Immunology Laboratory, Institute of Immunology, NUI Maynooth, Ireland and $\dagger$ Department of Veterinary Pathology, University College \\ Dublin, Ireland
}

\begin{abstract}
Summary
Background It has been proposed that T helper (Th)2-driven immune deviation in early life can be countered by Th1 inducing childhood infections and that such counter-regulation can protect against allergic asthma.

Objective To test whether Th1-inducing infection with Bordetella pertussis protects against allergic asthma using well-characterized murine models.

Methods Groups of mice were sensitized to ovalbumin (OVA) in the presence or absence of $B$. pertussis, a well-characterized Th1 inducing respiratory infection. Immunological, pathological and physiological parameters were measured to assess the impact of infection on immune deviation and airway function.

Results We demonstrate that OVA sensitization does not affect the development of B. pertussisspecific immune responses dominated by IgG2a and IFN- $\gamma$ and does not impair Th1-mediated clearance of airway infection. In contrast, B. pertussis infection at the time of sensitization modulated the response to OVA and significantly reduced total serum and OVA-specific IgE. The pattern of cytokine responses, in particular OVA-specific IL-5 responses in the spleen was also modulated. However, B. pertussis did not cause global suppression as IL-10 and IL-13 levels were enhanced in OVA-stimulated spleen cell cultures and in lavage fluid from infected co-sensitized mice. Histopathological examination revealed that B. pertussis infection prior to OVA sensitization resulted in increased inflammation of bronchiolar walls with accompanying hyperplasia and mucous metaplasia of lining epithelia. These pathological changes were accompanied by increased bronchial hyper-reactivity to methacholine exposure.

Conclusion Contrary to the above premise, a Th1 response induced by a common childhood infection does not protect against bronchial hyper-reactivity, but rather exacerbates the allergic asthmatic response, despite modulation of immune mediators.
\end{abstract}

Keywords allergy, bacterial, inflammation, lung, Th1/Th2 cells

Submitted $\square$ 2003; revised $\square$ 2004; accepted 26 May 2003

\section{Introduction}

Asthma is a chronic disease of the respiratory tract that has increased dramatically in prevalence in western society [1]. The inflammatory response in asthma is tightly associated with airway hyper-responsiveness (AHR), increased mucus production and an infiltration of the bronchial mucosa with $\mathrm{CD}^{+} \mathrm{T}$ cells [2]. There is evidence of an altered local $\mathrm{T}$ cell response in favour of $\mathrm{T}$ helper (Th) 2 cytokine release (IL-4, IL-5 and IL-13) resulting in B cell isotype switching to IgE, mast cell, eosinophil and basophil recruitment and production of a wide range of inflammatory mediators [3]. The resulting pulmonary inflammation leads to bronchoconstriction and ultimately to airway remodelling [4].

Correspondence: B. P. Mahon, Mucosal Immunology Laboratory, Institute of Immunology, National University of Ireland Maynooth, Maynooth, Co. Kildare, Ireland. E-mail: bpmahon@may.ie
The current understanding of the pathophysiology of allergic asthma is that it results from a breakdown in the normal tolerance to inhaled antigens, associated with Th2 cytokine production $[5,6]$. The murine ovalbumin (OVA) model of AHR exhibits many of the features of human asthma, including airway hyper-reactivity, airway inflammation and increased serum IgE levels [7, 8]. This model has been used extensively to probe mechanisms of asthma [7, 9].

The increased incidence of asthma has been linked to improved sanitation in industrialized societies, which in turn has reduced the incidence of childhood infections [10]. One current attempt to explain these observations, loosely termed the hygiene hypothesis, states that childhood asthma develops as a result of decreased exposure to infectious agents during infancy and early childhood, which results in the persistence of the neonatal Th1 deficit, thereby predisposing the child to atopic disease [11]. While Th2 cells promote airway inflammation in asthma, it has been proposed that because Th1 cells antagonize Th 2 cell function, immune deviation towards Th1 
may be protective in asthma $[12,13]$. One prediction arising from the above hypothesis is that a powerful Th1-inducing infection during or prior to airway sensitization should diminish or protect against Th2-mediated allergic asthma.

Bordetella pertussis is a Gram-negative bacterium that causes the severe infant disease whooping cough. B. pertussis respiratory challenge of mice is a well-characterized model of airway Th1-induced immunity, which correlates well to immunity in humans [14]. Recovery from infection is associated with the development of $B$. pertussis-specific Th1 cells in both humans and mice [15]. Th1 cells producing IFN$\gamma$ play an essential, non-redundant role in the clearance of the bacteria from the respiratory tract [16]. Murine respiratory challenge by aerosol administration of the bacteria has been used extensively for studies of $B$. pertussis immunity and pathogenesis and although mice lack the characteristic cough, in other respects the course of infection and many of the systemic effects are similar to those observed in infants [17]. In order to test the above hypothesis, we used the Th1 driving $B$. pertussis model, in combination with the murine OVA model of allergic asthma. Based on the prediction above, prior infection with $B$. pertussis might be expected to reduce OVA-induced Th2-mediated AHR and immunopathology.

Our findings demonstrate that although dampening of the Th2 response was seen at the local and systemic level, OVA sensitization during $B$. pertussis infection led to enhanced production of airway IL-10 and IL-13, coupled with a subsequent increase in AHR and pathology. This suggests that although IL-10 may be regarded as a regulatory cytokine, it has broader functions that may not always protect against inflammatory disease. These data have implications with regard to the validity of the hygiene hypothesis and raise concerns regarding therapies based on the conversion of Th2-dominated allergic inflammatory responses into Th1-dominated responses based on protective effects of Th1 cells in allergy and asthma.

\section{Materials and methods}

Animals

Six- to eight-week old female BALB/c (Harlan, UK) mice were used under the guidelines of the Irish Department of Health and the research ethics committee of the National University of Ireland Maynooth.

\section{Aerosol infection}

Respiratory infection was initiated by aerosol challenge with $B$. pertussis strain $\mathrm{W} 28$, following growth under agitation conditions at $37^{\circ} \mathrm{C}$ in Stainer-Scholte liquid medium. Bacteria from a log-phase culture were resuspended at a concentration of $2 \times 10^{10} \mathrm{CFU} / \mathrm{mL}$ in $1 \%(\mathrm{w} / \mathrm{v})$ casein in $0.9 \%(\mathrm{w} / \mathrm{v})$ saline. The challenge inoculum was administered to two groups of mice on 0 day (Bp and BpOVA groups). Administration was by aerosol over a period of $15 \mathrm{~min}$ using a nebulizer. Groups of four or more mice were killed at various time points after aerosol challenge to assess the number of viable $B$. pertussis in the lungs. Remaining mice received a similar aerosol of sterile saline alone.

\section{Immunization and airway delivery of OVA}

Two groups of 6-8-week-old female BALB/c mice (OVA and BpOVA) were sensitized by i.p. injection of $100 \mu \mathrm{g}$ OVA (Grade V; Sigma, Dorset, UK) emulsified in 2\% Alhydrogel ${ }^{\circledR}$ adjuvant (Superfos Biosector, Sweden) at 10 and 24 days after bacterial or saline challenge. Control groups (Ctrl and Bp) received saline alone (i.p.). On 35, 36 and 37 days, OVA and BpOVA-sensitized mice received $50 \mu \mathrm{g}$ OVA intra-nasally, whereas Ctrl and Bp groups received saline only.

\section{Enumeration of viable bacteria in the lungs}

Lungs were removed aseptically into $1 \mathrm{~mL}$ of sterile physiological saline with $1 \%$ casein. One hundred microliotres of serially diluted homogenate from individual lungs were placed onto triplicate Bordet-Gengou agar plates and the number of $\mathrm{CFU}$ determined after incubation at $37^{\circ} \mathrm{C}$ for 4 days. Results are reported as the mean number of $B$. pertussis $\mathrm{CFU}$ for individual lungs from four or more mice.

\section{Bronchoalveolar lavage}

Bronchoalveolar lavage (BAL) fluids were obtained by repeat administration and aspiration of $0.5 \mathrm{~mL}$ volumes (total $5 \mathrm{~mL}$ ) of phospate-buffered saline (PBS) via cannulation of the trachea of mice from three experiments $(n=5)$. Cells from the lavage fluid were recovered by centrifugation at $300 \mathrm{~g}$ for 6 min and resuspended in PBS; total leucocytes were counted and cytospin preparations were stained with a combined Alcian blue/Discombe's stain to determine the differential cell count. Supernatants were collected for cytokine analysis and stored at $-80^{\circ} \mathrm{C}$.

\section{Measurement of ovalbumin- and Bordetella pertussis-} specific antibody

OVA- and B. pertussis-specific-IgG1, IgG2a, IgG2b and IgG3 present in collected sera were measured by ELISA as previously described [16, 18]. Briefly, plates were coated with OVA protein $(5 \mu \mathrm{g} / \mathrm{mL})$ or sonicated B. pertussis antigen $(1 \mu \mathrm{g} /$ $\mathrm{mL}$ ) overnight at $4{ }^{\circ} \mathrm{C}$. After blocking and the addition of serum samples, alkaline phosphatase-labelled rat anti-mouse $\operatorname{IgG} 1, \operatorname{IgG} 2 \mathrm{a}, \operatorname{IgG} 2 \mathrm{~b}$ and $\operatorname{IgG} 3$ (Pharmingen) were used to detect OVA- and $B$. pertussis-specific antibody as previously described [19]. Total and OVA-specific IgE was measured using a rat anti-mouse IgE monoclonal antibody (Pharmingen). The IgE concentration was expressed as micrograms per millilitre after comparison with murine IgE standards.

\section{$T$ cell proliferation assays}

Spleen cells $\left(2 \times 10^{6} / \mathrm{mL}\right)$ from infected, sensitized and control mice ( $n=4$ or more per group) were tested for in vitro proliferation against heat-inactivated $B$. pertussis $\left(1 \times 10^{4} \mathrm{CFU} / \mathrm{mL}\right)$, OVA $(20 \mu \mathrm{g} / \mathrm{mL})$, Concanavalin A (Con A) $(5 \mu \mathrm{g} / \mathrm{mL}$, positive control), or medium alone (negative control). After $72 \mathrm{~h}$, cell proliferation was assessed by liquid scintillation counting of $\left[{ }^{3} \mathrm{H}\right]$-Thymidine incorporation and results were expressed as mean CPM of triplicate wells $\pm \mathrm{SE}$. At the 72-h time-point, culture supernatants were sampled for cytokine analysis, although the kinetics of cytokine produc- 
tion varies this time-point has previously proved acceptable for detection of most cytokines [14].

\section{Cytokine measurement}

Concentrations of IL-4, IL-5, IL-10, IL-13 and IFN- $\gamma$ from spleen and broncho-alveolar lavage fluid (BALF) were assessed by ELISA (Pharmingen). Cytokine concentrations were calculated by comparison with known cytokine standards as previously described [16].

\section{Whole-body plethysmography}

Airway responsiveness was assessed by methacholine (MCh)induced airflow obstruction from conscious mice using wholebody plethysmography (Buxco Electronics, USA) as previously described [20]. Pulmonary airflow obstruction was measured by enhanced pause $(\mathrm{PenH})$, a value determined from the ratio of expiratory time and relaxation time to peak expiratory flow and peak inspiratory flow and thought to correlate with airway responsiveness. Measurements were obtained after exposure of mice for $3 \mathrm{~min}$ to PBS (baseline) followed by incremental doses $(3.3-50 \mathrm{mg} / \mathrm{mL})$ of $\mathrm{MCh}$ delivered by aerosol [21].

\section{Respiratory tract histology}

Animals ( $n=5$ per group per experiment) were killed at 37 days. Lungs were removed, fixed in a paraformaldehyde/ lysine/periodate fixative, paraffin embedded, sectioned and stained using the haematoxylin and eosin (H\&E), Discombe's (identification of eosinophils)/Alcian blue (identification of mucus), Periodic Acid-Schiff (assessment of basement membrane thickness), azure-A (identification of mast cells) and
Van Gieson (identification of fibrosis) methods. Histopathological changes evident were graded according to a semiquantitative scoring system as mild, moderate or severe by two researchers without prior knowledge of the treatment group (Table 2). All experiments were performed at least twice $(n=5)$ on each occasion.

\section{Results} Ovalbumin sensitization does not impair T helper 1-
mediated mechanisms of bacterial clearance

In order to examine the effects of immune cross-regulation we tested the effect of OVA sensitization upon the development of a protective Th1 response to infection. Groups of mice were sensitized to OVA in the presence or absence of a prior $B$. pertussis infection (Table 1). The kinetics of bacterial clearance from the lungs of experimental animals were monitored by performing colony counts on whole-lung homogenates at different times post-bacterial challenge. Mice received either saline (Ctrl and OVA) or viable B. pertussis (Bp and BpOVA) by aerosol. This was followed by OVA (OVA and BpOVA) or sham sensitization (Table 1). Groups infected with $B$. pertussis (Bp and combined BpOVA groups) showed similar kinetics of bacterial clearance. No bacteria were recovered from the OVA or Ctrl group (Fig. 1), which were uninfected but received saline by aerosol. Bacterial burden in the $\mathrm{Bp}$ and BpOVA groups peaked at 10 days and declined thereafter. By 35 days-post-challenge, both the Bp and the BpOVA groups showed complete bacterial clearance (Fig. 1). Therefore, sensitization with OVA does not impair the effector function associated with the Th1-mediated clearance of a bacterial disease.

Table 1. Experimental design

\begin{tabular}{lllll}
\hline & Time (days) & & \\
\cline { 2 - 5 } Description & 0 & 10 & 24 & $35 / 36 / 37$ \\
\hline Control & Saline aerosol & Saline (i.p.) & Saline (i.p. and i.n.) \\
Bp infection & Bp aerosol infection & Saline (i.p.) & Saline (i.p. and i.n.) \\
OVA sensitization & Saline aerosol & OVA (i.p.) & OVA (i.p and i.n.) & Saline (i.n.) \\
Bp infection and OVA sensitization (BpOVA) & Bp aerosol infection & OVA (i.p.) & OVA (i.p and i.n.) & OVA (i.n.) \\
\hline
\end{tabular}

*Groups of 6-8-week-old female BALB/c mice ( $n=4$ or more per replicate per time-point) were treated as follows: Control (Ctrl) mice were sham infected on 0 day and sham sensitized at 10 days and 24 days. A second group (Bp) were infected with Bordetella pertussis at 0 day and sham sensitized at 10 day and 24 days. The third group (OVA) were sham infected but sensitized with OVA ( $100 \mu \mathrm{g}$, i.p.) at 10 and 24 .days and then again ( $50 \mu \mathrm{g}$ i.n.) at $24,35,36$, and 37 days. The final group (BpOVA) were infected with B. pertussis on 0 day, and sensitized as above.

Table 2. Histological assessment of airway pathology

\begin{tabular}{|c|c|c|c|c|c|c|c|c|c|}
\hline \multirow[b]{2}{*}{ Treatment group } & \multirow{2}{*}{$\begin{array}{l}\text { Epithelial mucous } \\
\text { metaplasia }\end{array}$} & \multirow{2}{*}{$\begin{array}{l}\text { Epithelial } \\
\text { hyperplasia }\end{array}$} & \multirow{2}{*}{$\begin{array}{l}\text { Smooth muscle } \\
\text { hypertrophy }\end{array}$} & \multicolumn{6}{|c|}{ Peri-airway inflammation* } \\
\hline & & & & Overall & $\mathrm{E}$ & $\mathrm{N}$ & L & $M$ & $\mathrm{~F}$ \\
\hline Control & - & - & - & - & - & - & - & - & - \\
\hline $\mathrm{Bp}$ & - & + & + & + & - & + & ++ & - & - \\
\hline OVA & ++ & ++ & ++ & ++ & + & ++ & ++ & - & - \\
\hline BpOVA & +++ & +++ & ++ & +++ & ++ & +++ & +++ & - & - \\
\hline
\end{tabular}

A semi-quantitative score $(-$, absent; + , mild; ++ , moderate; +++ , severe) was assigned to features of airway pathology observed.

*Peri-airway inflammation assessed in terms of overall degree and of numbers of infiltrating eosinophils (E), neutrophils ( $N$ ), lymphocytes, plasma cells and macrophages $(\mathrm{L})$, mast cells $(\mathrm{M})$ and in terms of circumscribing fibrosis $(\mathrm{F})$. Observations are representative of at least two experiments where $n=5$ or more in each case. 


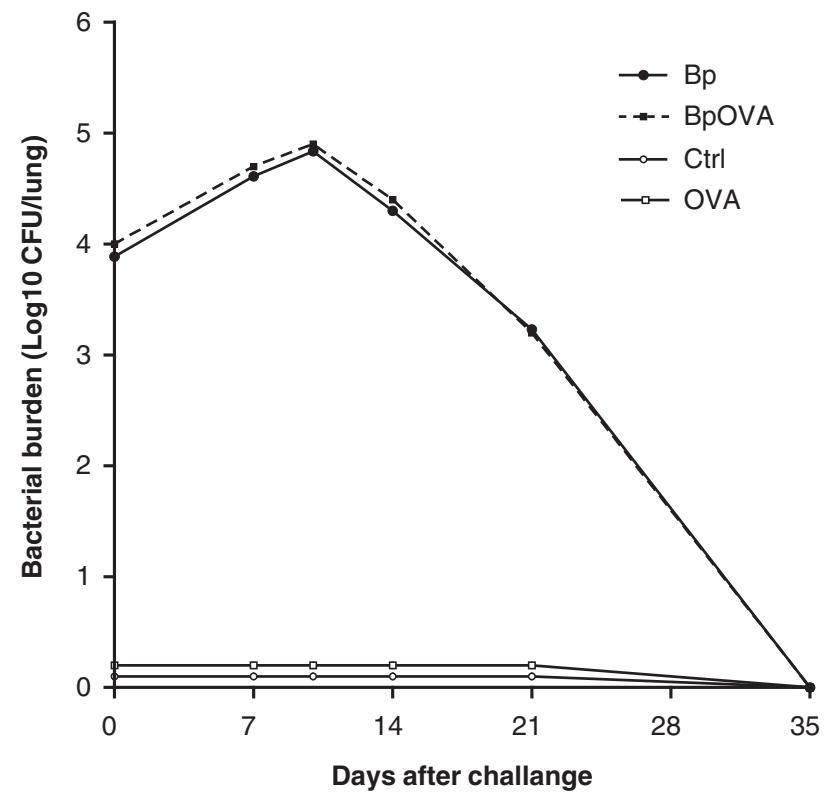

Fig. 1. Course of Bordetella pertussis infection in experimental and control (Ctrl) mice. Groups of mice were killed at intervals after challenge and the number of viable bacteria estimated by performing colony counts on individual lung homogenates. Results are representative from two experiments and are presented as mean CFU in the lungs determined individually per group from four mice at each time point. Data for Ctrl and ovalbumin (OVA) groups have been offset from zero for clarity.

\section{Bordetella pertussis suppresses ovalbumin-specific humoral immune responses}

Although OVA-induced sensitization does not impair Th1 clearance of $B$. pertussis, we wanted to examine the influence of $B$. pertussis infection on responses associated with OVA Th2 sensitization. OVA-specific IgG was not detected from mice infected with $B$. pertussis only; similarly $B$. pertussisspecific IgG could not be detected in OVA-sensitized animals, suggesting no significant cross-reaction between the two immunogens occurred (Figs 2a and b). An analysis of antibody subclasses revealed that infection induced greater serum titres of B. pertussis-specific IgG2a than IgG1 (Figs 2a and $b$ ), consistent with our previous findings [19]. Sensitization of infected mice with OVA (BpOVA) did not significantly alter this profile. OVA sensitization in the absence of infection resulted in strong antibody responses almost exclusively of the IgG1 subclass, consistent with a Th2 model of priming. In contrast to the minimal influence of OVA on the response to infection (Fig. 2a), bacterial B. pertussis infection suppressed or modulated immunity to OVA. For example, OVA-specific IgG1 titres were significantly lower $(P<0.001)$ in the combined group (Fig. 2b). Suppression was not confined to IgG subclasses. Total serum and OVAspecific $\operatorname{IgE}$ was also significantly reduced $(P<0.001)$ between the OVA and the Bp/OVA groups (Figs $2 \mathrm{c}$ and d), supporting a role for $B$. pertussis in suppressing or regulating the immune response to antigen exposure during infection.

Ovalbumin sensitization during Bordetella pertussis infection enhances airway Interleukin-10 and Interleukin-13

In order to dissect the nature of B. pertussis suppression, cellmediated immune responses were examined from spleen cultures. As previously reported [22], B. pertussis infection induced strong splenic proliferative and IFN $-\gamma$ responses but very little IL-5 (Figs 3a-c). This was consistent with the observed protection (Fig. 1) and the antibody subclass data (Fig. 2). Again, IFN- $\gamma$ was not significantly reduced by OVA sensitization (Fig. 3c). As expected, OVA sensitization alone induced significant IL-5 but no IFN- $\gamma$ (Figs $3 \mathrm{a}$ and c). However B. pertussis did influence cytokine responses to OVA. Reduced levels of IL-5 were detected in the combination group suggesting that $B$. pertussis suppressed Th2 responses to OVA, mirroring the reduction in titre of specific antibody detected. Interestingly $B$. pertussis infection did induce specific IL-10 as well as IL-13 responses (Figs $3 \mathrm{~b}$ and d). While OVA sensitization had little other effect on the immune response induced by infection, it significantly enhanced the levels of IL-10 and IL-13 $(P<0.01$ and $<0.01$, respectively) produced in response to the bacterium (Figs $3 b$ and d).

To extend these findings, we examined the levels of cytokines present in BALF. OVA sensitization, but not infection, induced IL-4 (Fig. 4a); however, prior infection with $B$. pertussis suppressed this. B. pertussis infection induced local IFN- $\gamma$, which was not reduced by OVA sensitization (Fig. 4d). Interestingly, while OVA sensitization induced IL-10 and IL-13 detectable in BALF, this was significantly $(P<0.01$ and $<0.01$, respectively) enhanced if sensitization followed infection (Figs $4 \mathrm{~b}$ and c).

\section{A T-helper 1 infection in the respiratory tract does not} protect, but exacerbates the allergic asthmatic response

It has been proposed that prior Th1 responses to bacterial infections protect against allergic disease by dampening the activity of Th2 effector cells. It might also be predicted that the suppressive or modulatory effects of $B$. pertussis outlined above would protect against Th2-driven pathology. We used whole-body plethysmography in order to measure airway reactivity in mice infected with $B$. pertussis prior to OVA sensitization in comparison with controls (Fig. 5). We found that contrary to the above premise, a Th1 response induced by infection in the respiratory tract did not protect against bronchial hyper-reactivity but rather exacerbated the allergic asthmatic response. Statistical analysis using two-way ANOVA showed that mice sensitized to OVA following $B$. pertussis infection displayed significantly greater bronchial hyperreactivity compared with OVA sensitized alone $(P<0.001)$ (Fig. 5). This demonstrates that infection with $B$. pertussis of the respiratory tract prior to sensitization results in increased airway reactivity and exacerbates the allergic response.

$B$. pertussis infection also modulated the quality of the inflammatory influx to the respiratory tract. There was a marked reduction in eosinophil numbers observed in BpOVA compared with OVA-sensitized airways (Table 3). Histological examination of lung tissue showed that pathological changes were largely focussed on bronchioles and adjacent peribronchiolar blood vessels with varying degrees of airway wall inflammation and smooth muscle hypertrophy accompanied by varying degrees of epithelial hyperplasia and mucous metaplasia (Fig. 6). A semi-quantitative histopathological scoring system was used to facilitate comparisons between groups (Table 2). Minimal changes were observed in 

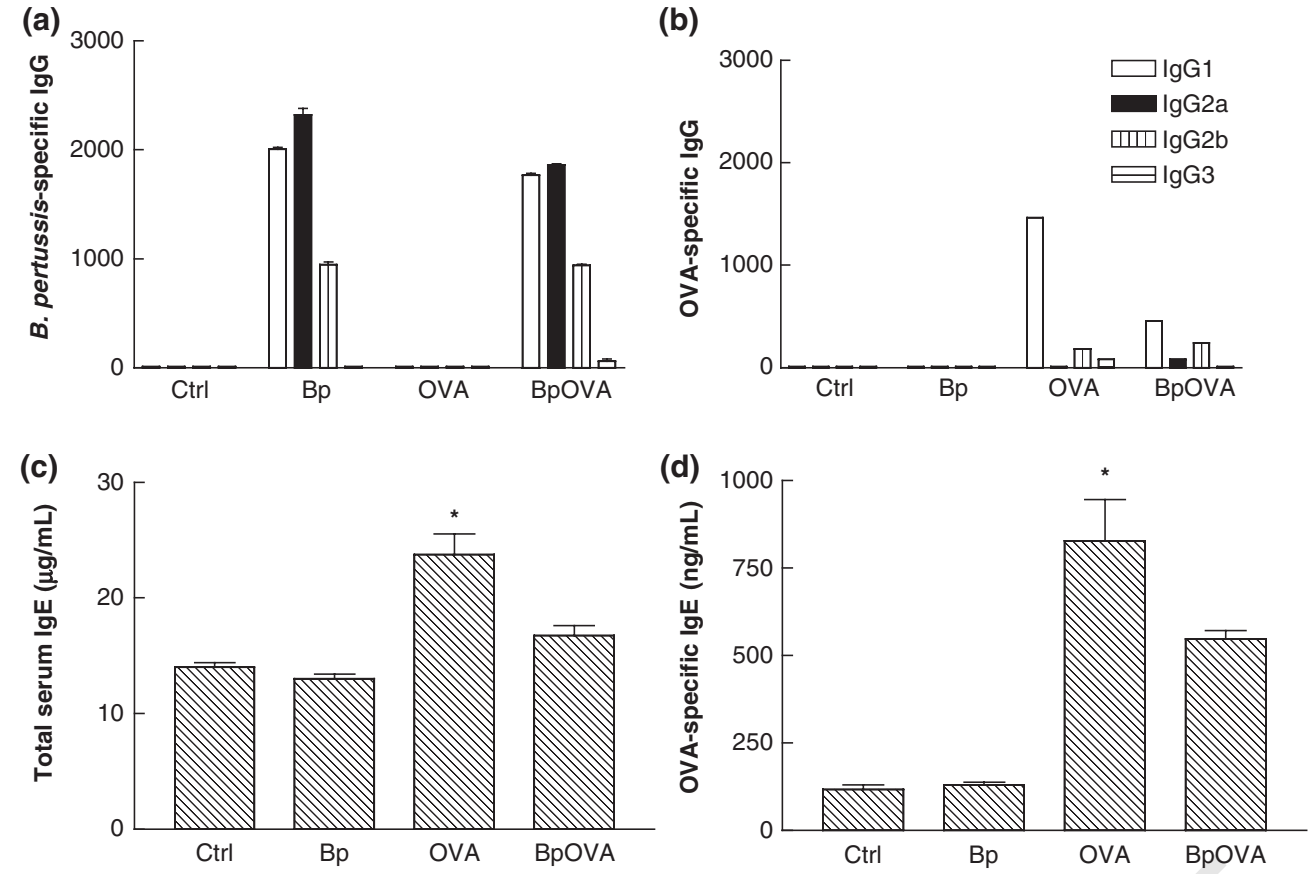

Fig. 2. Serum and ovalbumin (OVA)-specific IgE and IgG subclasses elicited by bacterial infection and allergic sensitization. (a) Bordetella pertussis and (b) OVAspecific serum antibody responses by IgG subclass elicited in control (Ctrl), infected (Bp), sensitized (OVA) mice, or in mice infected with B. pertussis prior to sensitization (BpOVA); expressed as geometric mean titre of antibody ( $\pm \mathrm{SE})$. (c) Total IgE and (d) OVA-specific IgE present in sera from each experimental group expressed as $\mu \mathrm{g} / \mathrm{mL}$ or $n g / m L$, respectively. OVA-specific $\lg E(\mathrm{ng} / \mathrm{mL})$ is a relative measure determined by adaptation of a standard IgE ELISA. Results are representative of three experiments from four animals performed independently in triplicate. * Statistical significance, $P<0.001$ compared with BpOVA-treated group. (a)

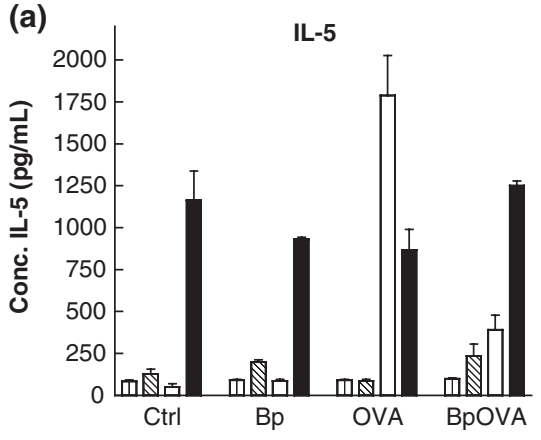

(c)

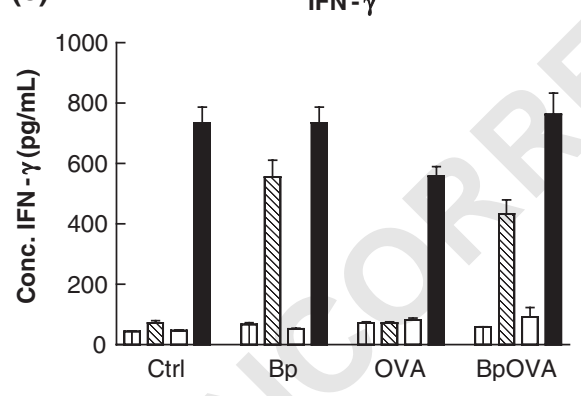

(b)

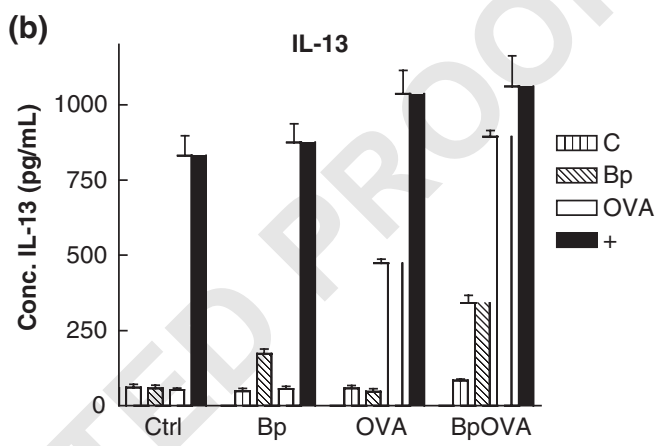

(d)

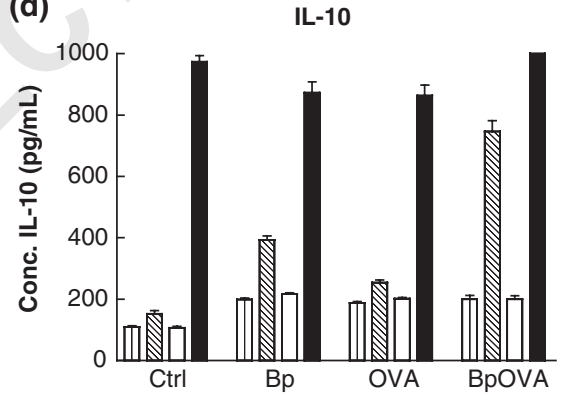

Fig. 3. Cell-mediated immune responses from spleen, elicited by bacterial infection and allergic sensitization. IL-5 (a), IL-13 (b), IFN- $\gamma$ (c), and IL-10 (d) responses from spleen cell cultures stimulated with medium alone (negative control, vertical shading), heat inactivated Bordetella pertussis sonicate at $1 \times 10^{4} \mathrm{CFU} /$ $\mathrm{mL}$ (hatched bar), ovalbumin (OVA) $(20 \mathrm{mg} / \mathrm{mL}$ ) (open bar) or Con A (positive control, black bar). Responses are representative of triplicate experiments each assay was performed in triplicate on individual samples from four mice per group and results are expressed as mean $( \pm \mathrm{SE})$. mice challenged with $B$. pertussis only, as infection had resolved by the 37 days time-point. OVA sensitization resulted in typical inflammation of airway walls with infiltration of eosinophils, neutrophils and lymphocytes (Fig. 6c). However, BpOVA mice displayed more severe airway wall inflammation with a greater degree of both epithelial hyperplasia and mucous metaplasia than Bp, OVA or control mice (Fig. 6d). Given that airway resistance $(R)$ is inversely proportional to the fourth power of the airway luminal radius $\left(r^{4}\right)$ even minimal narrowing caused by processes such as transmural inflammation, epithelial hyper- plasia or mucus exudation subsequent to epithelial mucous metaplasia can profoundly increase pulmonary resistance as indicated by plethysmography (Fig. 5).

\section{Discussion}

The present study demonstrates that prior infection with viable $B$. pertussis modulates the immune response induced by allergen sensitization. Infection suppresses antibody and cell- 


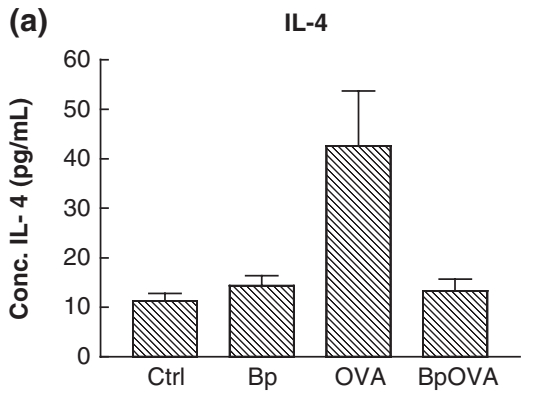

(c)

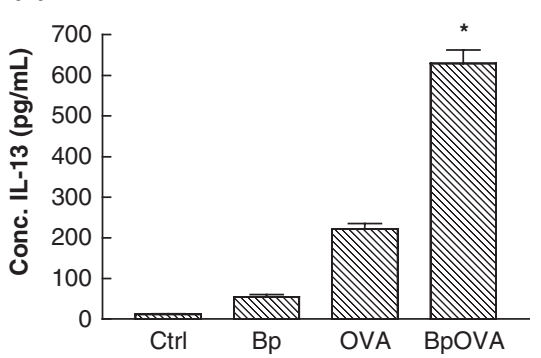

(b)

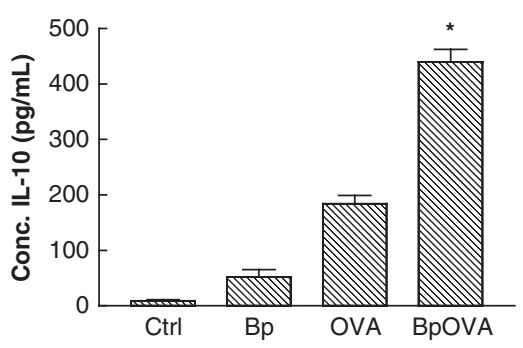

(d)

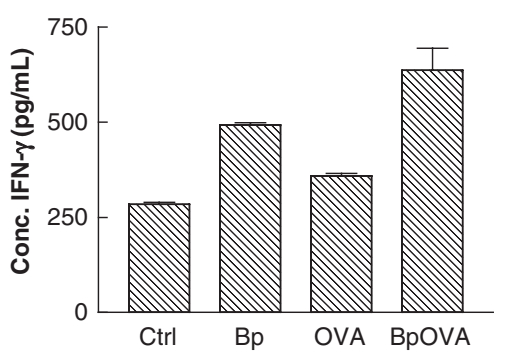

Fig. 4. Bordetella pertussis infection modulates the local cytokine response to allergen. Groups of mice were treated as described in the legend to Fig. 1. At 37 days, diluted bronchoalveolar lavage was pooled from five mice per group and concentrations of IL-4 (a), IL-10 (b), IL-13 (c) and IFN- $\gamma$ (d) responses determined by enzyme immunoassay. Results are representative of triplicate experiments, assays were performed in triplicate, values are expressed as mean \pm SE between experimental and control groups. ${ }^{\star} P<0.01$

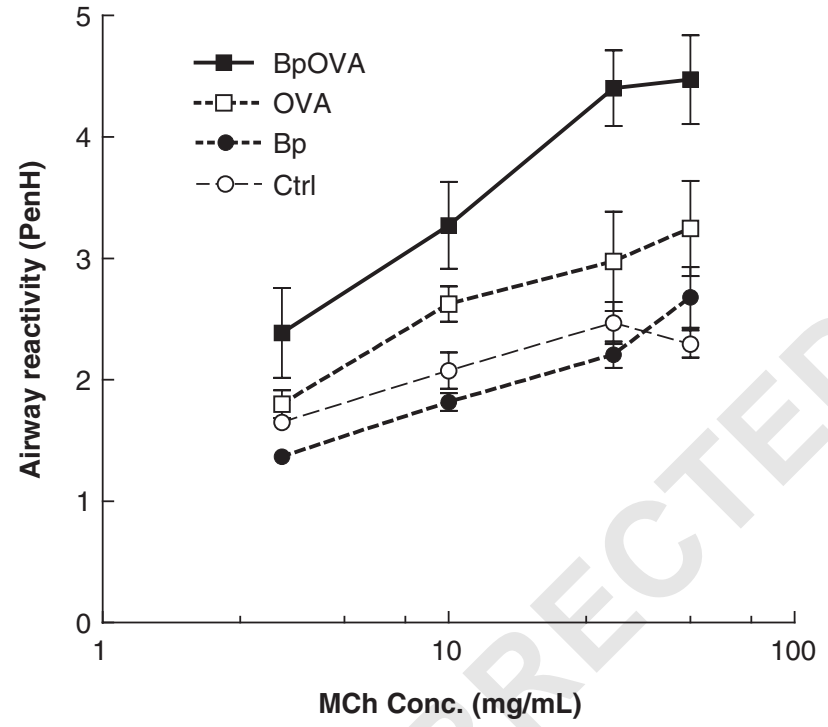

Fig. 5. Bordetella pertussis exacerbates bronchial hyper-responsiveness to sensitizing antigen. Groups of mice were treated as described in the legend to Fig. 1. At 37 days, airway hyper-reactivity in response to increasing concentrations of inhaled methacholine $(\mathrm{MCh})$ was measured by whole-body plethysmography. Results are representative of three experiments ( $n=4$ per group) and values are expressed as mean enhanced pause $(\mathrm{PenH}) \pm \mathrm{SE}$.

mediated responses against OVA locally and systemically, while enhancing the levels of the regulatory cytokine IL-10 and IL-13. Despite this modulation, $B$. pertussis exacerbates OVA-induced airway pathology, leading to the development of more pronounced allergen-induced airway inflammation as well as the induction of enhanced AHR.

Asthma is a chronic inflammatory disease of the airways, the prevalence of which has increased substantially in recent decades [24, 25]. The explanation that has attracted most attention is the hygiene hypothesis, which suggests that the increase in allergic disease is caused by a cleaner environment and fewer childhood infections [26]. The goal of this study was to test the hypothesis that a powerful Th1-mediated infection such as $B$. pertussis would diminish or protect in a murine model of allergic asthma. Zuany-Amorim et al. [27] used a similar model, but employed heat-killed Mycobacterium vaccae that was effective in blocking allergic inflammation but by a mechanism independent of IFN- $\gamma$. The same authors went on to find that mycobacteria induce IL-10producing regulatory $\mathrm{T}$ cells. Intriguing recent data from McGuirk et al. [15] have shown that the filamentous haemagluttinin component of $B$. pertussis behaves in a similar way. Our observation of IL-10 in lavage fluid and following in vitro stimulation of spleen cells supports the latter finding. In the case of the protection generated by mycobacterial exposure, it is proposed that IL-10 has an essential role in modulating the immune system by inducing a shift from an allergen-specific Th2 response [28]. In the present study, we observe a similar modulation but this does not result in protection against airway hyper-reactivity, implying that although the restoration of a putative balance between Th1 and Th2 is an attractive theory, it is unlikely to provide a universal explanation of the pathogenesis of asthma.

Studies with Th1 and Th2 cells in diabetes mellitus and autoimmune encephalomyelitis indicate that cross-regulation does not always operate and in some instances can be unexpectedly harmful [29]. For example, Genain et al. [30] showed in a model of multiple sclerosis that a shift in cytokine production from a Th1 to a Th2 pattern increased concentrations of pathogenic autoantibodies and in some instances exacerbated autoimmune disease. Pakala et al. [31] also showed that immune deviation towards a Th2 response did not reduce, but rather exacerbated pathology and disease. In the present study, the Th2-associated effect of OVA sensitization had little influence on the Th1-mediated clearance of a bacterial infection of the airways. In contrast, $B$. pertussis infection suppresses $\mathrm{IgG}$ and $\mathrm{IgE}$ responses associated with OVA sensitization. This provides compelling 
Table 3. Leucocytes present in BAL fluid

\begin{tabular}{llllrl}
\hline Group & $\begin{array}{l}\text { Total leucocytes } \\
\left(\times 10^{4}\right)\end{array}$ & $\begin{array}{l}\text { Eosinophils } \\
\left(\times 10^{4}\right)\end{array}$ & $\begin{array}{l}\text { Macrophages } \\
\left(\times 10^{4}\right)\end{array}$ & $\begin{array}{l}\text { Lymphocytes } \\
\left(\times 10^{4}\right)\end{array}$ \\
\hline Control & $5.0 \pm 0.5$ & $<0.005$ & $3.9 \pm 2.0$ & $0.2 \pm 0.1$ & $\begin{array}{l}\text { Neutrophils } \\
\left(\times 10^{4}\right)\end{array}$ \\
Bp & $5.0 \pm 0.4$ & $<0.005$ & $4.6 \pm 0.9$ & $1.1 \pm 0.7$ & $0.005 \pm 0.1$ \\
OVA & $8.0 \pm 1.7$ & $4.1 \pm 0.9$ & $2.9 \pm 1.2$ & $0.6 \pm 0.1$ & $0.5 \pm 0.2$ \\
BpOVA & $5.0 \pm 0.8$ & $2.4 \pm 0.8^{\star}$ & $2.1 \pm 0.8$ & $0.4 \pm 0.1$ & $0.5 \pm 0.3$ \\
\hline
\end{tabular}

Groups of mice were killed (37 days), bronchoalveolar lavage (BAL) cells were collected, counted, and cytospin preparations stained to obtain the differential leucocyte count. Data represent mean ( $\pm \mathrm{SE}$ ) values; $n=5-8$ mice per experiment.

${ }^{*} P<0.05$ vs. OVA group.
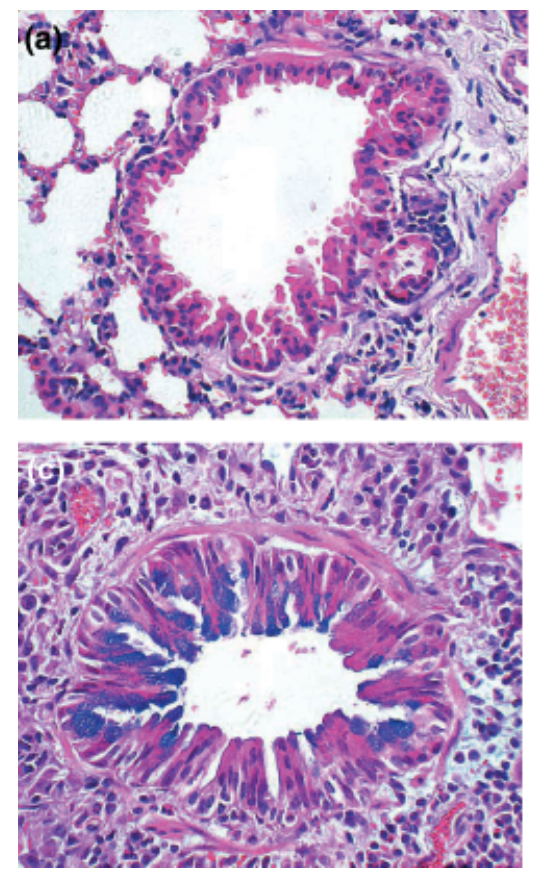
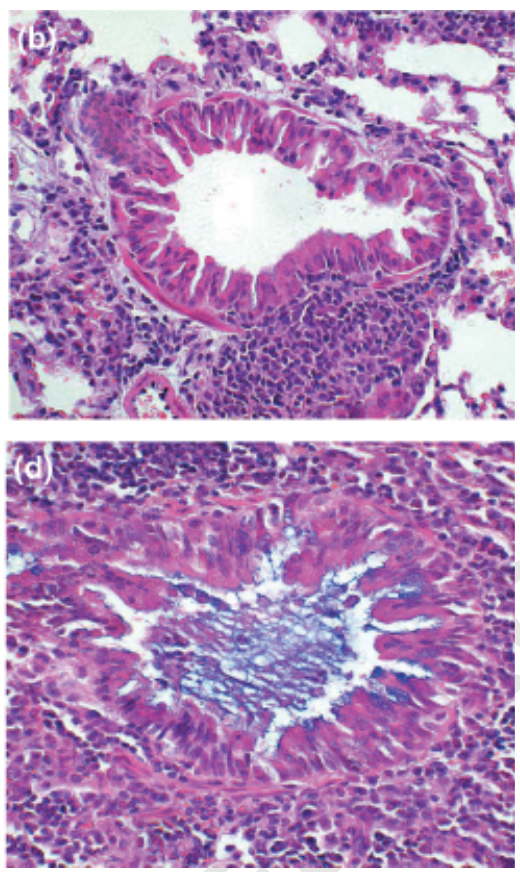

Fig. 6. Bordetella pertussis increases the severity of airway pathology to sensitizing antigen. Photomicrographs a-d illustrate representative morphological changes in transverse sections of bronchioles at 37 days ( $n=5$ per group). (a) Control group; (b) B. pertussis infected group (mild mural and peri-airway inflammation evident); (c) ovalbumin (OVA)-sensitized group illustrating moderate mural and peri-airway inflammation with accompanying moderate mucus metaplasia (blue staining goblet cells) and hyperplasia of epithelium; (d) Combined B. pertussis/OVA-treated group illustrating severe mural and peri-airway inflammation, moderate epithelial hyperplasia and severe mucous metaplasia with accompanying mucus plugging of the lumen $(P)$. All sections stained with a combined Discombes/Alcian blue stain. Original magnification $\times 400$ evidence that $B$. pertussis powerfully modulates the response to the third party antigens. These data are again consistent with studies in which $M$. vaccae injection to OVA-immunized mice significantly suppressed serum $\operatorname{IgE}$ [32] but are in direct contrast to Zuany-Amorim et al. [27] in which they failed to see any effect on $\operatorname{IgG} 2$ a levels or serum IgE. Although $M$. vaccae and $B$. pertussis provoke similar immune responses, radically different pathologies are induced. The resolution of this paradox may lie in the different aetiologies of both $M$. vaccae and B. pertussis. Respiratory challenge by $M$. vaccae causes minimal epithelial damage and limited airway pathology. In stark contrast $B$. pertussis causes significant damage to the epithelial lining of the airways [33]. This is mediated through a bacterial virulence factor called tracheal cytotoxin, which induces IL-1 $\beta$ and reactive nitrogen intermediates that bring about ciliostasis, followed by airway remodelling $[34,35]$. Thus, while $M$. vaccae and $B$. pertussis induce very similar immune responses, it may be that during $B$. pertussis infection there is a combination of epithelial damage, IFN- $\gamma$, IL-10 and IL-13 production that has profound influences on the epithelium and its local environment, which serves to exacerbate rather than protect against asthma.

In asthma, the bronchial epithelium is highly abnormal with structural changes involving separation of columnar cells from their basal attachments and functional changes resulting in increased expression and release of pro-inflammatory cytokines and growth factors [36]. Beneath the damaged and dysfunctional epithelium lie increased numbers of subepithelial myofibroblasts that deposit interstitial collagens causing thickening of the basement membrane [4]. These effects are seen in the present study in the OVA group (Fig. 6c) but are more prominent in the combination group that received B. pertussis prior to OVA sensitization (Fig. 6d). Evidence suggests that the epithelium should not be viewed in isolation, as airway smooth muscle cells contribute to the perpetuation of airway inflammation and airway remodelling [37]. Grunstein et al. [38] has suggested that IL-10 may play an important role in allergic asthma by acting directly on the sensitized airway smooth muscle itself. The present study suggests that although IL-10 may be a regulatory cytokine, it has broader functions that may not always protect against inflammatory disease, particularly if there has been damage to the superficial epithelium. Lee et al. [39] have also demonstrated that IL-10 induces IL-13 production in vivo and that this induction was responsible for the mucus, but not the inflammatory and fibrotic effects of IL-10. This would appear to be consistent with our own data (Figs $3 \mathrm{~b}$ and d, 4b and c) where we see an increase in both IL-10 and IL-13 at the systemic and local level. The decrease in eosinophilia (Table 
2) observed in the BpOVA group is most likely because of the modulation of IL-5 responses in these mice (Fig. 3a). IL-5 is a cytokine necessary for the regulation of eosinophil growth, differentiation, activation and survival and plays a critical role in the recruitment of eosinophils to the lung [40]. Similar responses were observed by $\mathrm{Wu}$ et al. [41] using murine cytomegalovirus infection in conjunction with the murine model of OVA-induced allergic airway disease. Previous studies in humans have demonstrated that IL-13 mRNA and protein levels are elevated in the lungs of atopic and nonatopic asthmatics [42, 43], suggesting that overproduction of IL-13 may predispose toward the development of both types of asthma [43]. Walter et al. [44] showed that an OVA-specific Th2 line generated from IL-13 $3^{-1-}$ mice, which produced high levels of IL-4 and IL-5, but not IL-13, failed to induce AHR, demonstrating the essential role of IL-13 in the development of AHR. IL-13 may also increase AHR directly. IL-13 induces smooth muscle proliferation in vitro [45] and can aid contractions of tracheal smooth muscle [46]. Airway smooth muscle cells have also been shown to express IL-13 receptors, including both components of the IL-13R complex [47]. Amrani et al. [48] have suggested that increased levels of IFN- $\gamma$ in asthmatic individuals may promote AHR and exacerbate asthma by directly modulating contractile responses. OVA sensitization of infected mice in the combination group induced significant levels of IFN- $\gamma$ detectable in the BALF (Fig. 4d), suggesting that IFN- $\gamma$ may contribute to the observed exacerbation of pathology (Fig. 6d). This correlates well with studies in humans where increased IFN- $\gamma$ was seen in asthmatic patients compared with normal subjects $[49,50]$. It has also been shown that AHR can manifest independently of pulmonary inflammation [51] although this was not seen in this study. Respiratory syncytial virus (RSV), commonly associated with lower lung infections in infancy is also known to exacerbate asthma [52, 53]. Matsuse et al. [54] found that the effect of RSV infection varies depending upon the inflammatory context of the lung. Both primary and recurrent RSV infections augment ongoing allergic inflammation, however, in the absence of allergic sensitization, the effects of RSV were transient. Comparable with our own study with $B$. pertussis, Lukacs et al. [55] found that an initial RSV infection can initiate a pro-asthmatic environment that promotes a more severe asthmatic response, even when the allergic response is initiated at a time after clearance of the RSV-induced reactions. Likewise, OVA sensitization of mice infected intravenously with Listeria monocytogenes, converts a non-lethal infection to a lethal disease. In that model IL-10 plays a critical role in the suppression of anti-listerial resistance in OVA-immunized mice [56]. Other groups have shown that heat-killed Mycobacterium bovis-BCG suppressed the development of OVA-induced airway eosinophila $[57,58]$. In many of these studies the timing of sensitization and infection influence the outcome, however, the exacerbation mediated by $B$. pertussis appears to be persistent and long lived (data not shown). Taken together, these studies suggest that pathogens may induce an altered cytokine environment in the context of airway remodelling that ultimately provides for an exacerbated asthmatic-type response [55].

Immune counter-regulation based on Th1/Th2 mechanisms or even regulatory $\mathrm{T}$ cells secreting IL-10 have been suggested as mechanisms that could protect against asthma. We show here that this response must be viewed in the broader context of the host-pathogen interaction. B. pertussis fulfils many of the criteria for a potent immunomodulator that should protect against asthma. However, the potent influence on airway remodelling during infection means that this bacterium has the opposite effect. This study clearly shows that while the hygiene hypothesis is an attractive theory, it is of limited validity as currently stated. Furthermore, our results raise concerns regarding immunomodulatory therapies aimed at the conversion of Th2-dominated allergic inflammatory responses into Th1-dominated responses based on counterregulation that may be of limited efficacy, or even harmful.

\section{Acknowledgements}

We thank Mrs Sheila Worrell, Mr Joseph Brady and Mrs Bernadette Ruane for their expert technical assistance. This work was supported by grants from the Irish HEA PRTL programme (Darren Ennis). Bernard Mahon is a Wellcome Trust/HRB new blood fellow (GR 054236).

\section{References}

1 Umetsu DT, McIntire JJ, Akbari O, Macaubas C, DeKruyff RH. Asthma: an epidemic of dysregulated immunity. Nat Immunol 2002; 3:715-20.

2 Wilder JA, Collie DD, Wilson BS, Bice DE, Lyons CR, Lipscomb MF. Dissociation of airway hyperresponsiveness from immunoglobulin E and airway eosinophilia in a murine model of allergic asthma. Am J Respir Cell Mol Biol 1999; 20:1326-34.

3 Ying S, Humbert M, Barkans J et al. Expression of IL-4 and IL-5 mRNA and protein product by CD4+ and CD8+ T cells, eosinophils, and mast cells in bronchial biopsies obtained from atopic and nonatopic (intrinsic) asthmatics. J Immunol 1997; 158:3539-44.

4 Holgate ST, Davies DE, Lackie PM, Wilson SJ, Puddicombe SM, Lordan JL. Epithelial-mesenchymal interactions in the pathogenesis of asthma. J Allergy Clin Immunol 2000; 105:193-204.

5 Del Prete G, Maggi E, Parronchi P et al. IL-4 is an essential factor for the IgE synthesis induced in vitro by human $\mathrm{T}$ cell clones and their supernatants. J Immunol 1988; 140:4193-8.

6 Swain SL, Weinberg AD, English M, Huston G. IL-4 directs the development of Th2-like helper effectors. J Immunol 1990; 145:3796-806.

7 Haczku A, Takeda K, Hamelmann E et al. CD23 deficient mice develop allergic airway hyperresponsiveness following sensitization with ovalbumin. Am J Respir Crit Care Med 1997; 156:1945-55.

8 Padrid PA, Mathur M, Li X et al. CTLA4Ig inhibits airway eosinophilia and hyperresponsiveness by regulating the development of Th1/Th2 subsets in a murine model of asthma. Am J Respir Cell Mol Biol 1998; 18:453-62.

9 Herz U, Lumpp U, Da Palma JC et al. The relevance of murine animal models to study the development of allergic bronchial asthma. Immunol Cell Biol 1996; 74:209-17.

10 Strachan DP. Family size, infection and atopy: the first decade of the hygiene hypothesis. Thorax 2000; 55 (Suppl. 1):S2-10.

11 Tantisira KG, Weiss ST. Childhood infections and asthma: at the crossroads of the hygiene and Barker hypotheses. Respir Res 2001; 2:324-7.

12 Lipscomb MF, Wilder JA. Immune dysregulation as a cause for allergic asthma. Curr Opin Pulm Med 1999; 5:10-20. 
13 Mosmann TR, Coffman RL. TH1 and TH2 cells: different patterns of lymphokine secretion lead to different functional properties. Annu Rev Immunol 1989; 7:145-73.

14 Mills KH, Ryan M, Ryan E, Mahon BP. A murine model in which protection correlates with pertussis vaccine efficacy in children reveals complementary roles for humoral and cell-mediated immunity in protection against Bordetella pertussis. Infect Immunol 1998; 66:594-602.

15 McGuirk P, McCann C, Mills KH. Pathogen-specific T regulatory 1 cells induced in the respiratory tract by a bacterial molecule that stimulates interleukin 10 production by dendritic cells: a novel strategy for evasion of protective $\mathrm{T}$ helper type 1 responses by Bordetella pertussis. J Exp Med 2002; 195:221-31.

16 Mahon BP, Sheahan BJ, Griffin F, Murphy G, Mills KH. Atypical disease after Bordetella pertussis respiratory infection of mice with targeted disruptions of interferon-gamma receptor or immunoglobulin mu chain genes. J Exp Med 1997; 186:1843-51.

17 Sato Y, Izumiya K, Sato H, Cowell JL, Manclark CR. Aerosol infection of mice with Bordetella pertussis. Infect Immunol 1980; 29:261-6.

18 Morokata T, Ishikawa J, Ida K, Yamada T. C57BL/6 mice are more susceptible to antigen-induced pulmonary eosinophilia than $\mathrm{BALB} / \mathrm{c}$ mice, irrespective of systemic $\mathrm{T}$ helper $1 / \mathrm{T}$ helper 2 responses. Immunology 1999; 98:345-51.

19 Mahon BP, Brady MT, Mills KH. Protection against Bordetella pertussis in mice in the absence of detectable circulating antibody: implications for long-term immunity in children. J Infect Dis 2000; 181:2087-91.

20 Hamelmann E, Gelfand EW. Animal models of airway sensitization. Curr Protocols Immunol 1999.

21 Hamelmann E, Schwarze J, Takeda K et al. Noninvasive measurement of airway responsiveness in allergic mice using barometric plethysmography. Am J Respir Crit Care Med 1997; 156:766-75

22 Mahon BP, Ryan MS, Griffin F, Mills KH. Interleukin-12 is produced by macrophages in response to live or killed Bordetella pertussis and enhances the efficacy of an acellular pertussis vaccine by promoting induction of Th1 cells. Infect Immunol 1996; 64:5295-301.

23 Magnan AO, Mely LG, Camilla CA et al. Assessment of the Th1 $\mathrm{Th} 2$ paradigm in whole blood in atopy and asthma. Increased IFNgamma-producing CD8(+) T cells in asthma. Am J Respir Crit Care Med 2000; 161:1790-6.

24 Gergen PJ, Weiss KB. Changing patterns of asthma hospitalization among children: 1979 to 1987. JAMA 1990; 264:1688-92.

25 Hansen G, Berry G, DeKruyff RH, Umetsu DT. Allergen-specific Th1 cells fail to counterbalance Th2 cell-induced airway hyperreactivity but cause severe airway inflammation. J Clin Invest 1999; 103:175-83.

26 Bousquet J, Jeffery PK, Busse WW, Johnson M, Vignola AM. Asthma. From bronchoconstriction to airways inflammation and remodeling. Am J Respir Crit Care Med 2000; 161:1720-45.

27 Zuany-Amorim C, Manlius C, Trifilieff A et al. Long-term protective and antigen-specific effect of heat-killed Mycobacterium vaccae in a murine model of allergic pulmonary inflammation. J Immunol 2002; 169:1492-9.

28 Zuany-Amorim C, Sawicka E, Manlius C et al. Suppression of airway eosinophilia by killed Mycobacterium vaccae-induced allergen-specific regulatory T-cells. Nat Med 2002; 8:625-9.

29 Lafaille JJ, Keere FV, Hsu AL et al. Myelin basic protein-specific $\mathrm{T}$ helper 2 (Th2) cells cause experimental autoimmune encephalomyelitis in immunodeficient hosts rather than protect them from the disease. J Exp Med 1997; 186:307-12.

30 Genain CP, Abel K, Belmar N et al. Late complications of immune deviation therapy in a nonhuman primate. Science 1996; 274:2054-7.

31 Pakala SV, Kurrer MO, Katz JD. T helper 2 (Th2) T cells induce acute pancreatitis and diabetes in immune-compromised nonobese diabetic (NOD) mice. J Exp Med 1997; 186:299-306.
32 Wang $\mathrm{CC}$, Rook GA. Inhibition of an established allergic response to ovalbumin in BALB/c mice by killed Mycobacterium vaccae. Immunology 1998; 93:307-13.

33 Mahon BP, Mills KH. Interferon-gamma mediated immune effector mechanisms against Bordetella pertussis. Immunol Lett 1999; 68:213-7.

34 Flak TA, Goldman WE. Autotoxicity of nitric oxide in airway disease. Am J Respir Crit Care Med 1996; 154:S202-6.

35 Luker KE, Collier JL, Kolodziej EW, Marshall GR, Goldman WE. Bordetella pertussis tracheal cytotoxin and other muramyl peptides: distinct structure-activity relationships for respiratory epithelial cytopathology. Proc Natl Acad Sci USA 1993; 90:2365-9.

36 Holgate ST. Epithelial damage and response. Clin Exp Allergy 2000; 30 (Suppl. 1):37-41.

37 Lazaar AL, Panettieri RA Jr. Airway smooth muscle as an immunomodulatory cell: a new target for pharmacotherapy? Curr Opin Pharmacol 2001; 1:259-64.

38 Grunstein MM, Hakonarson H, Leiter J et al. Autocrine signaling by IL-10 mediates altered responsiveness of atopic sensitized airway smooth muscle. Am J Physiol Lung Cell Mol Physiol 2001; 281:L1130-7.

39 Lee CG, Homer RJ, Elias JA et al. Transgenic overexpression of interleukin (IL)-10 in the lung causes mucus metaplasia, tissue inflammation, and airway remodeling via IL-13-dependent and independent pathways. J Biol Chem 2002; 277:35466-74.

40 Lopez AF, Sanderson CJ, Vadas MA et al. Recombinant human interleukin 5 is a selective activator of human eosinophil function. J Exp Med 1988; 167:219-24.

$41 \mathrm{Wu}$ CA, Puddington L, Thrall RS. Murine cytomegalovirus infection alters $\mathrm{Th} 1 / \mathrm{Th} 2$ cytokine expression, decreases airway eosinophilia, and enhances mucus production in allergic airway disease. J Immunol 2001; 167:2798-807.

42 Naseer T, Minshall EM, Hamid Q. Expression of IL-12 and IL-13 mRNA in asthma and their modulation in response to steroid therapy. Am J Respir Crit Care Med 1997; 155:845-51.

43 Humbert M, Durham SR, Kay AB et al. Elevated expression of messenger ribonucleic acid encoding IL-13 in the bronchial mucosa of atopic and nonatopic subjects with asthma. J Allergy Clin Immunol 1997; 99:657-65.

44 Walter DM, McIntire JJ, Umetsu DT. Critical role for IL-13 in the development of allergen-induced airway hyperreactivity. J Immunol 2001; 167:4668-75.

45 Wei LH, Jacobs AT, Morris SM Jr, Ignarro LJ. IL-4 and IL-13 upregulate arginase I expression by cAMP and JAK/STAT6 pathways in vascular smooth muscle cells. Am J Physiol Cell Physiol 2000; 279:C248-56.

46 Tliba O, Deshpande D, Amrani Y. L-13 enhances agonist-evoked calcium signals and contractile responses in airway smooth muscle. Br J Pharmacol 2003; 140:1159-62.

47 Heinzmann A, Mao XQ, Shirakawa T et al. Genetic variants of IL-13 signalling and human asthma and atopy. Hum Mol Genet 2000; 9:549-59.

48 Amrani Y, Moore PE, Hoffman R, Shore SA, Panettieri RA Jr. Interferon-gamma modulates cysteinyl leukotriene receptor-1 expression and function in human airway myocytes. Am J Respir Crit Care Med 2001; 164:2098-101.

49 Cho SH, Stanciu LA, Begishivili T, Bates PJ, Holgate ST, Johnston SL. Peripheral blood CD4+ and CD8+ T cell type 1 and type 2 cytokine production in atopic asthmatic and normal subjects. Clin Exp Allergy 2002; 32:427-33.

50 Cembrzynska-Nowak M, Szklarz E, Inglot AD, TeodorczykInjeyan JA. Elevated release of tumor necrosis factor-alpha and interferon-gamma by bronchoalveolar leukocytes from patients with bronchial asthma. Am Rev Respir Dis 1993; 147:291-5.

51 Makela MJ, Kanehiro A, Borish L et al. IL-10 is necessary for the expression of airway hyperresponsiveness but not pulmonary 
inflammation after allergic sensitization. Proc Natl Acad Sci USA 2000; 97:6007-12.

52 Johnson TR, Graham BS. Secreted respiratory syncytial virus G glycoprotein induces interleukin-5 (IL-5), IL-13, and eosinophilia by an IL-4-independent mechanism. J Virol 1999; 73:8485-95.

53 Nadel JA, Busse WW. Asthma. Am J Respir Crit Care Med 1998; 157:S130-8.

54 Matsuse H, Behera AK, Mohapatra SS et al. Recurrent respiratory syncytial virus infections in allergen-sensitized mice lead to persistent airway inflammation and hyperresponsiveness. J Immunol 2000; 164:6583-92.

55 Lukacs NW, Lincoln P, Maassab H. Respiratory syncytial virus predisposes mice to augmented allergic airway responses via IL-13mediated mechanisms. J Immunol 2001; 167:1060-5.
56 Mizuki D, Miura T, Nakane A. Interference between host resistance to Listeria monocytogenes infection and ovalbumininduced allergic responses in mice. Infect Immun 2001; 69:1883-8.

57 Major T, Wohlleben G, Reibetanz B, Erb KJ. Application of heat killed Mycobacterium bovis-BCG into the lung inhibits the development of allergen-induced Th2 responses. Vaccine 2002; 20:1532-40.

58 Nahori MA, Lagranderie M, Vargaftig BB. Effects of Mycobacterium bovis $\mathrm{BCG}$ on the development of allergic inflammation and bronchial hyperresponsiveness in hyper-IgE BP2 mice vaccinated as newborns. Vaccine 2001; 19:1484-95. 


\section{Author Query Form}

\section{Journal CEA}

\section{Article 2042}

\section{Dear Author,}

During the copy-editing of your paper, the following queries arose. Please respond to these by marking up your proofs with the necessary changes/additions. Please write your answers on the query sheet if there is insufficient space on the page proofs. Please write clearly and follow the conventions shown on the attached corrections sheet. If returning the proof by fax do not write too close to the paper's edge. Please remember that illegible mark-ups may delay publication

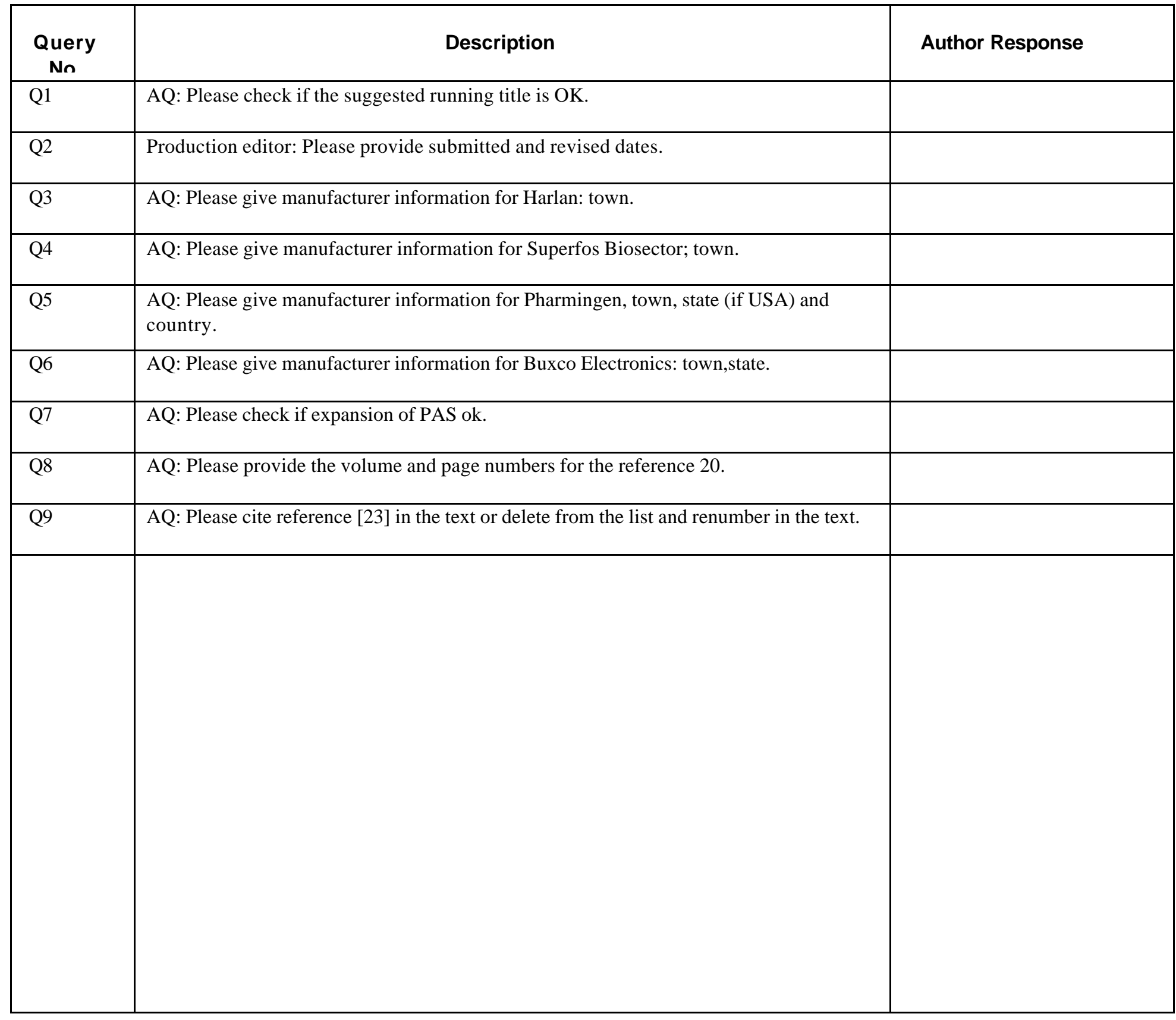




\section{Please correct and return this set}

Please use the proof correction marks shown below for all alterations and corrections. If you wish to return your proof by fax you should ensure that all amendments are written clearly in dark ink and are made well within the page margins.

\begin{tabular}{|c|c|c|}
\hline Instruction to printer & Textual mark & Marginal mark \\
\hline Leave unchanged & ... under matter to remain & Stet \\
\hline $\begin{array}{l}\text { Insert in text the matter } \\
\text { indicated in the margin }\end{array}$ & $h$ & $\begin{array}{l}\text { New matter followed by } \\
h\end{array}$ \\
\hline Delete & $\mapsto$ through matter to be deleted & $\delta$ \\
\hline Delete and close up & E through matter to be deleted & व \\
\hline $\begin{array}{l}\text { Substitute character or } \\
\text { substitute part of one or } \\
\text { more word(s) }\end{array}$ & $\begin{array}{l}/ \text { through letter or } \mapsto \text { through } \\
\text { word }\end{array}$ & New letter or new word \\
\hline Change to italics & - under matter to be changed & U \\
\hline Change to capitals & $\equiv$ under matter to be changed & $\equiv$ \\
\hline Change to small capitals & $=$ under matter to be changed & $=$ \\
\hline Change to bold type & m under matter to be changed & $m$ \\
\hline Change to bold italic & $\bar{\sim}$ under matter to be changed & \\
\hline Change to lower case & Encircle matter to be changed & \\
\hline Change italic to upright type & (As above) & \\
\hline Insert 'superior' character & $\begin{array}{l}/ \text { through character or } \wedge \text { where } \\
\text { required }\end{array}$ & $\begin{array}{l}y \text { under character } \\
\text { e.g. } 2 y\end{array}$ \\
\hline Insert 'inferior' character & (As above) & $\boldsymbol{L}$ over character e.g. $\mathbf{L}$ \\
\hline Insert full stop & (As abo & 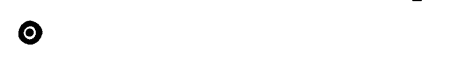 \\
\hline Insert comma & (As above) & , \\
\hline Insert single quotation marks & (As above) & $y$ and/or $y$ \\
\hline $\begin{array}{l}\text { Insert double quotation } \\
\text { marks }\end{array}$ & (As above) & "y and/or $y$ \\
\hline Insert hyphen & (As above) & (4) \\
\hline Start new paragraph & $\sqrt{-10}$ & $\sqrt{5}$ \\
\hline No new paragraph & 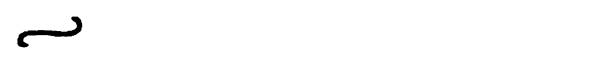 & 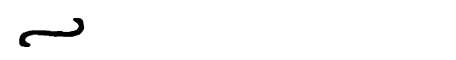 \\
\hline Transpose & 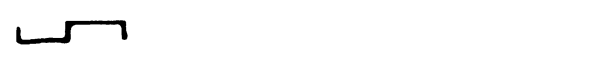 & 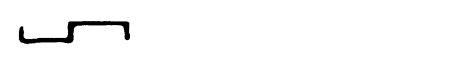 \\
\hline Close up & linking $=$ letters & $=$ \\
\hline Insert space between letters & $\boldsymbol{h}$ between letters aff & \# \\
\hline Insert space between words & $\boldsymbol{h}$ between words affected & $\#$ \\
\hline Reduce space between letters & $\uparrow$ between letters affected & $T$ \\
\hline Reduce space between words & $\boldsymbol{T}$ between words affected & \\
\hline
\end{tabular}

